\title{
THE
}

\section{Sustainable Scholarship Forum}

Andrée J. Rathemacher

University of Rhode Island Library, andree@uri.edu

Follow this and additional works at: https://digitalcommons.uri.edu/lib_ts_pubs

Part of the Library and Information Science Commons

\section{Citation/Publisher Attribution}

Rathemacher, Andrée J.. "Sustainable Scholarship Forum." , (2010). doi: 10.1016/j.serrev.2010.05.010.

This Article is brought to you for free and open access by the Technical Services at DigitalCommons@URI. It has been accepted for inclusion in Technical Services Department Faculty Publications by an authorized administrator of DigitalCommons@URI. For more information, please contact digitalcommons-group@uri.edu. 


\section{Sustainable Scholarship Forum}

Andrée J. Rathemacher

On March 30, 2010, about sixty librarians and a handful of publisher representatives attended the "Sustainable Scholarship" forum in Boston, hosted by Ithaka S+R. Topics included JSTOR's forthcoming Current Scholarship Program, the economics of university press journals publishing, recent ITHAKA $S+R$ research on faculty attitudes and the withdrawal of print collections, and ejournal preservation services offered by PORTICO.

\section{JSTOR's Current Scholarship Program}

The first presentation of the day concerned the Current Scholarship Program, JSTOR's new initiative to provide access to current journal issues on the JSTOR platform. Mary Rose Muccie (director, Current Journals Program) and Jason Phillips (director, Outreach \& Preservation Services) explained the motivation for the program and the benefits for libraries, as well as providing details on publisher partners, titles, and ordering options. For the Current Journals Program, JSTOR has partnered with a number of academic press journal publishers to provide access to current journal issues on a redesigned JSTOR platform. The new JSTOR platform will be the only platform on which current issues the journals are offered: for example, JSTOR will take the place of the University of California Press's CALIBER platform. Publishers, not JSTOR, will set the price for access to current issues, which will be licensed individually or as part of collections. The speakers emphasized that participating publishers — primarily 
university presses, scholarly societies, and small presses — share with JSTOR a commitment to fair and sustainable publishing models that will serve the scholarly community over the long term and lead to the widest possible dissemination of research. The Current Scholarship Program is a response to demand from libraries, faculty and other researchers, and publishers for access to current content on the JSTOR platform. The Program will provide economies of scale in publishing technology, which will help maintain a diverse community of publishers.

Researchers will benefit from the ability to efficiently search interdisciplinary journal content on a single platform.

As of the date of the forum, 163 titles from fourteen publishers were confirmed participants in the Current Scholarship Program, with the greatest number of titles from the University of Chicago Press, the University of California Press, Indiana University Press, the University of Illinois Press, and Penn State University Press. Current Scholarship Program titles will debut on an enhanced JSTOR platform which will offer more formats, including full-text HTML and born-digital PDF. Multimedia capabilities, including the ability to deliver images, audio, video, and GIS data, as well as tools that will allow publishers to manage their own content, will help JSTOR evolve into a more broad-based platform that will be able to host multiple content types in the future. Perhaps most significantly, the new JSTOR platform will allow for open searching and browsing by non-subscribers, enhancing the role of JSTOR as a discovery tool for scholarly content. Subject searching capabilities are in development. 
Muccie and Phillips outlined the benefits to libraries of the Current Scholarship Program at the system level, as well as the level of individual institutions. The Current Scholarship Program will bolster the health of university press and society publishers by helping them deliver and market their content in a cost-effective manner. In doing so, the system of scholarly communication will be strengthened and the risk of loss of scholarly output will be lessened. At the institutional level, libraries will enjoy reasonable and transparent pricing, as participating publishers are committed to the principle of achieving the widest possible access to their published research, as well as long-term sustainability. Since JSTOR tends to be one of the most heavily used electronic resources at many institutions, adding current content to the JSTOR platform will increase the discoverability and accessibility of the content. Further, since current and back issues for any given journal title or collection of titles will be on a single license and a single platform, administrative costs to subscribing libraries will be reduced.

The speakers explained that subscription options for libraries will be flexible. Libraries can subscribe to current issues only or full runs of a particular title called "Enhanced Single Titles." Current Scholarship Program titles will be able to be purchased in pre-defined collections that align with JSTOR back issue collections, or libraries may create custom collections of any combination of titles. Long term preservation and post-cancellation access will be handled by Portico. Muccie and Phillips encouraged subscribers to order Current Scholarship Program journals directly from JSTOR, since all that is involved is a rider to their existing license agreement; however, JSTOR will be working with subscription agents if libraries prefer that approach. A final title list with pricing will be available in summer 2010, at which time orders 
will be taken for 2011 subscriptions. Access to Current Scholarship Program titles on the JSTOR platform will begin in January 2011.

\section{University Press Journals Publishing: The Reasonable Response}

The next speaker on sustainable scholarship was Nick Lindsay (journals manager at MIT Press) who discussed the challenges and problems facing university presses. Lindsay began by mentioning a number of top-ranked, society based journals that recently moved from university presses to large commercial publishers. For example, the Journal of the European Economic Association moved from MIT Press to Wiley-Blackwell; the Washington Quarterly moved from MIT Press to Taylor \& Francis; the American Anthropological Association moved their journals from the University of California Press to Wiley-Blackwell; and the American Sociological Association stopped self-publishing their journals to publish with SAGE. This trend of journals migrating from university presses to large commercial publishers has been going on for years but is accelerating.

The reasons behind the migration are primarily financial. The commercial publishers offer signing bonuses and higher royalty rates that university presses cannot match. Publications are often the main source of income for societies, and in difficult economic times when memberships are dropping and younger scholars are not joining, they find it necessary to maximize the revenue from their publications in order to continue to operate. In addition, the big commercial publishers have international offices and sales and marketing resources far beyond the scope of university presses, resources that can help increase subscriptions. Finally, larger 
publishers can achieve economies of scale on production costs from paper to information technology.

The net result of this shift away from university presses to large commercial publishers is higher journal prices, especially for institutional subscribers. While not revealing the names of specific titles or publishers, Lindsay offered examples of the degree of price increases often seen when journals switch to commercial publishers. In two years, the price of "Journal X" increased 61 per cent, the price of "Journal Y" rose 116 per cent in three years, and the price of one unnamed journal package increased 27 percent in three years.

In another example illustrating current difficulties achieving sustainability in scholarly publishing, Lindsay noted that one title still published by MIT Press, Computational Linguistics, chose to move to an open access model in 2009. This increased usage of the title by 300 percent, but the Association of Computational Linguistics no longer has any subscription revenue with which to cover production costs. In a similar example provided by Lindsay, Cornell's ArXiv eprint repository recently announced that it was moving to a collaborative business model in which arXiv would remain free for readers and submitters, but institutions that benefit most from arXiv would be asked to make voluntary contributions in support of operating costs and system enhancements. The pressure on MIT Press from the open access movement, however, is nothing compared to the pressure with competition from commercial publishers, Lindsay noted. 
Lindsay next posed the question of how university presses can compete and survive in this difficult environment. The first strategy, he explained, is to work with like-minded organizations. For example, MIT Press publishes journals for the MacArthur Foundation, the American Academy of Arts and Sciences, New England Quarterly, Inc., and the International Society for Art, Science and Technology. The missions of these organizations overlap with the mission of MIT Press, which is to achieve the broadest dissemination of scholarly content possible. In addition, all of these organizations are financially stable, so maximizing revenue does not have to be their highest goal.

A second strategy for university presses is innovation in technology, as well as content packaging. For example, CogNet is an online resource comprised of bundled content from MIT Press geared toward the brain and cognitive science community. A third strategy for university presses is to be nimble. MIT Press has demonstrated such nimbleness in its marketing campaigns by producing inexpensive podcasts featuring MIT Press authors, shifting to HTML email campaigns and moving as much marketing online as possible, and increasing co-marketing opportunities between the journals and books divisions. Finally, in recognition that not all journals must fit into the same mold, university presses can compete by providing individual attention to clients (e.g. by accommodating a variety of production processes).

In conclusion, Lindsay acknowledged that university press journals programs are in a tough spot, acting as a "farm team for the major leagues," that is, large commercial publishers. University press-published journals are not likely to disappear altogether, but they are in danger of 
becoming diminished and irrelevant as the publishers of last resort. Lindsay, however, finds reasons to be optimistic in the fact that there are societies which choose to forego larger profits in favor of the mission of disseminating scholarship. Further, publishing a journal with an academic press affiliated with a prestigious institution like Massachusetts Institute of Technology, Johns Hopkins University, or the University of California provides instant credibility for startup journals and helps in attracting authors and reviewers. There are still significant and important journals being published by university presses, and for every journal that ceases publication, many new journals spring up. The "scholarly brotherhood" of university press publishers, scholarly societies, and libraries remain committed to serving the research community. They are looking toward new ways to collaborate to ensure the health and sustainability of scholarly communication.

\section{Faculty Attitudes 2009: Results from Ithaka S+R's Latest Nationwide Survey}

Ross Housewright (research analyst, Ithaka S+R) previewed the results of the latest in a series of surveys of faculty members in the United States, focusing on the changing attitudes of faculty about the transition of scholarly journals and other materials from print to electronic format. Ithaka S+R's survey of faculty attitudes has been conducted every three years since 2000 . The latest survey took place in 2009 and resulted in 3,000 responses from faculty members at fouryear colleges and universities in the U.S. (1)

One question in the survey concerned the print-to-electronic transition for current issues of journals. Faculty were asked to indicate their agreement with the strongly-worded statement, "If 
my library cancelled the current issues of a print version of a journal but continued to make them available electronically, that would be fine with me." The majority of all faculty agree with this statement, with faculty in the sciences agreeing most strongly (over 80 percent), followed by social sciences faculty (about 75 percent) and humanities faculty (60 percent). These disciplinary differences are significant, yet when compared with responses from previous surveys, humanities scholars now agree with the statement at a greater rate than sciences faculty did in 2003. Further, the agreement from faculty in each discipline increased at the same rate between each administration of the survey.

In another part of the survey, faculty were asked to indicate their agreement with the statement, "I am completely comfortable with journals I use regularly ceasing print versions and publishing in electronic-only form." Faculty responses to this statement were more conservative, with only about 50 percent of scientists, about 40 percent of social scientists, and about 25 percent of humanists strongly agreeing. This presents an apparent contradiction when compared with the previous statement. It suggests that while an increasing number of faculty do not feel that they need access to print journals locally, they care that journals exist in print somewhere. The reasons for this are unclear, possibly reflecting a sense that journals that publish in print have higher prestige than those that do not or a preference, perhaps, for browsing through print journals received at home. More data is needed.

Despite increasing comfort with the idea of their library cancelling current issues of a print journal in favor of online access, fewer than 40 percent of faculty surveyed agree with the 
statement: "Assuming that electronic collections of journals are proven to work well and are readily accessible, I would be happy to see hard-copy collections discarded and replaced entirely by electronic collections." Nonetheless, agreement with this statement doubled between 2006 and 2009, which suggests growing awareness by faculty of the financial and space pressures confronting libraries. It also reflects increasing comfort with the idea of discarding print collections, as faculty have realized their work has not been affected as libraries have withdrawn print volumes in recent years. In addition, a declining number of faculty agree that it will "always be crucial" for their or some other college or university library "to maintain hard-copy collections of journals."

The contradictory responses by faculty to issues surrounding the transition of scholarly materials from print to electronic format present challenges for academic libraries which are facing pressure to draw down print collections to make room for new services. Faculty are not rewarding libraries for preserving print journals nor giving them a mandate to do so, yet the majority of faculty feel that their library should not discard older print journals. For current issues of journals, faculty understand that there has been a switch to electronic access, yet faculty feel that discarding back issues in favor of online access would be taking something away.

\section{The Print-to-Electronic Transition: What to Withdraw}

Housewright transitioned from the survey of faculty attitudes to Ithaka S+R's 2009 report titled What to Withdraw: Print Collections Management in the Wake of Digitization. (2) Housewright explained that as a greater share of journal back files are digitized, libraries face pressure to 
reduce the size of their corresponding print collections. However, individual libraries

contemplating the withdrawal of print collections lack information about what other libraries are discarding and preserving. A lack of system-wide coordination may result in all print copies of a journal being lost, when, in fact, it may be important to preserve at least some print copies. The objective of the What to Withdraw report is to provide information about community-wide preservation needs to assist the decision-making processes of individual libraries regarding the withdrawal of general collections of published scholarly journals.

Housewright presented four rationales for the preservation of print journals at the system level. First, at least some print copies of a journal should be preserved to fix scanning errors that are discovered at a later point in time, errors which occur even in cases where strict quality control was employed during the original scanning. A second reason to retain print is to re-scan journals that were initially scanned using inadequate scanning standards and practices. This might be especially important for journals with significant image content. Third, some digitized materials are not preserved adequately through deposit in a trusted digital repository and are therefore more subject to loss. Finally, access to some digital content is not technologically reliable or is subject to license terms and conditions or monopoly pricing practices that could compromise future access. These system-wide rationales for retaining print copies of a journal are in addition to any local concerns such as local scholarly needs or campus politics.

Ithaka S+R's study determined that in an ideal scenario the minimum time horizon for the retention of some print copies of a journal system-wide is twenty years. The ideal scenario 
assumes that journals were digitized according to high-quality standards, that active errorcorrection is taking place, that the electronic files are archived using a reliable digital preservation solution, that the journals are not image-intensive, and that access is based on reliable terms and conditions. As long as titles that meet these criteria are preserved in print format somewhere in the system, they are safe candidates for local withdrawal.

Ithaka S+R commissioned Candace Yano, an operations researcher at the University of California, Berkeley, to develop a model for the number of copies of a journal digitized according to the ideal scenario that would be needed to meet preservation goals. Operating with the assumption that dark archives have an annual "loss rate" of 0.1 percent, Yano concluded that over twenty years, two "perfect," non-circulating copies of a journal would be needed systemwide. Housewright made it clear that Ithaka $\mathrm{S}+\mathrm{R}$ was not recommending that only two copies be retained for only twenty years, but that this is the minimum number required to guarantee with 99 percent certainty that scanning errors can be fixed as they are discovered, that inadequately scanned journals can be re-scanned in higher quality, that content that is lost due to inadequate preservation can be re-scanned, and that materials with inadequate access provisions can be digitized by a competitor.

Next Housewright presented a decision-support tool for libraries developed by Ithaka $\mathrm{S}+\mathrm{R}$ as a result of this study. He noted that JSTOR-digitized titles fit the criteria for journals that can be safely withdrawn, as JSTOR uses high-quality scanning practices, actively corrects scanning errors as they are discovered, reliably preserves digital content, and employs reasonable and 
transparent license terms. In addition, JSTOR maintains two page-validated dark archives (at Harvard University and the University of California, Berkeley). Furthermore, JSTOR titles are widely held by academic libraries and are therefore available to be withdrawn. Ithaka S+R's decision-support tool details the preservation status of every JSTOR-digitized title, identifying titles that have relatively few images and are relatively completely held in both of the JSTOR dark archives. After downloading the tool at http://www.ithaka.org/ithaka-s-r/research/what-towithdraw/print-collections-decision-support-tool, a library can specify the JSTOR collections in which they participate and then view the list of JSTOR titles with an indication, for each title, of whether image and holdings criteria are met, if the library subscribes to the title, and if the title is actionable.

Housewright stressed that the decision-support tool is intended to help libraries identify potential easy opportunities for withdrawal if such titles also match local withdrawal criteria set by the library. The tool can provide information to supplement local decision-making processes, but it cannot substitute for those processes.

Plans are underway to continue the development of the decision-support tool. The tool may be enhanced to support volume and/or issue validation, to include holdings information based on additional print repositories, or to incorporate a greater range of quality paradigms in addition to the "ideal scenario" described above. More journals could be included in the tool, based on information about their print and digital preservation status. In addition, Ithaka $\mathrm{S}+\mathrm{R}$ hopes to enhance the decision-support tool to support consortial-driven planning and to interact more 
readily with local systems. It is the goal to expand coverage within the tool to 8-10,000 titles, or more than ten linear miles of shelving. Not only would libraries benefit through significant space-saving opportunities, but preservation of journal titles included in the tool would be assured, and through sharing information, regional and national print repositories would be able to develop with greater efficiency and effectiveness.

\section{The Expansion of Portico Long-Term Preservation Services}

The final presentation of the day was by Ken DiFiore (associate director, Outreach and Support Services, Portico) who began with an overview of Portico. Portico is a secure digital archive in which e-journals, e-books, and other electronic scholarly content are preserved. Like the JSTOR Current Scholarship Program, Portico benefits both publishers and libraries, balancing the needs and expectations of publishers with the interests of the academic community. By ensuring that digital scholarly content will remain available in the future, Portico helps libraries make a secure and reliable transition from print to electronic format materials, and by providing a shared infrastructure for digital preservation, Portico reduces system-wide preservation costs.

Portico was initiated by JSTOR with support from the Library of Congress and the Andrew W. Mellon Foundation and is currently supported by participating publishers and libraries. Portico receives content directly from publishers, preserving born-digital journals, as well as digitized journal back files. For libraries, membership in Portico serves as an "insurance policy" against lost digital content. Portico is essentially a "dark archive." When a "trigger event" occurs, that is, when digital content is lost, orphaned, or abandoned (as might happen when a publisher 
ceases operation, discontinues a title, or drops a back file), Portico opens its archive and provides member libraries with access to the content regardless of the libraries' past or current subscriptions to the material. Portico can also provide post-cancellation access for about 90 percent of the titles in the archive when access is not available directly from the publisher.

Currently, Portico archives over 10,000 journal titles published by over ninety journal publishers on behalf of over two thousand societies and associations. Of these titles, 55 percent are published by scholarly societies, 30 percent by commercial publishers, and 15 percent by university presses. Worldwide, 655 libraries are Portico participants, just over half of which are in the United States.

After explaining Portico's efforts in journal preservation, DiFiore addressed the expansion in mid-2008 of Portico to include the long-term preservation of e-books and digitized historical collections. Portico realizes that the uptake of e-books and d-collections is growing rapidly, yet the publishing market is volatile and post-cancellation mechanisms for these resources are uncertain. Portico is starting to preserve these materials now with a desire to avoid the lag between uptake and reliable preservation that was experienced with the adoption of e-journals. Since e-book formats are similar to those of e-journals, existing staff and content management systems can be readily adapted to non-journal material. Further, the inclusion of non-journal scholarly material in Portico is consistent with Ithaka's organizational mission to "preserve the scholarly record and to advance research and teaching in sustainable ways." 
DiFiore explained that Portico's e-book and d-collection preservation model is almost identical to the e-journal model. Library access is governed by the same trigger event scenarios and postcancellation options, content cannot be removed once deposited, and the managed preservation methodologies are the same. The only difference with e-books and d-collections is that instead of paying an annual participation fee, publishers pay a one-time setup fee. For libraries, Portico is considering separating the e-journal, e-book, and d-collection archives so that libraries can choose to support the preservation of the material types appropriate to their needs. Thus far, six e-book publishers are participating in Portico with over thirty thousand titles, and Portico is preserving ten d-collections from Gale Cengage.

DiFiore concluded by noting that the Center for Research Libraries (CRL) recently conducted a none-month audit of Portico and certified it a "trustworthy repository" based on metrics developed by CRL. Portico was the first digital preservation service to undergo this independent audit and is the only service to be certified at this time.

\section{Notes}

1. Roger C. Schonfeld and Ross Housewright, "Faculty Survey 2009: Key Strategic Insights for Libraries, Publishers, and Societies," http://www.ithaka.org/ithaka-s-r/research/faculty-surveys2000-2009/Faculty\%20Study\%20202009.pdf (accessed May 1, 2010).

2. Roger C. Schonfeld and Ross Housewright, "What to Withdraw? Print Collections Management in the Wake of Digitization," http://www.ithaka.org/ithaka-s-r/research/what-to- 
withdraw/What\%20to\%20Withdraw\%20-

\%20Print $\% 20$ Collections\%20Management $\% 20$ in $\% 20$ the $\% 20$ Wake\%20of\%20Digitization.pdf (accessed May 1, 2010). 